\title{
Selection of basalt fiber with resistance to concrete alkaline environment
}

\author{
Vitali Pastsuk ${ }^{1} \cdot$ Madis Kiisk $^{1} \cdot$ Rünno Lõhmus $^{1} \cdot$ Maido Merisalu $^{1} \cdot$ Sergei Kovaljov $^{2} \cdot$ Alex Biland $^{3}$. \\ Volodymyr Gulik ${ }^{1,4}$ (])
}

Received: 1 June 2020 / Accepted: 13 October 2020 / Published online: 19 October 2020

(c) Springer Nature Switzerland AG 2020

\begin{abstract}
Due to a growing interest in basalt fibers as a reinforcing material for concrete, it becomes necessary to study behavior of such fibers and their interaction with the concrete matrix. Basalt fibers have prospective mechanical and processability properties, as well as good cost-effectiveness when used as concrete reinforcement. However, alkali resistance properties of basalt fiber are rather weak. Three types of basalt fibers from various manufacturers are presented, which were produced from different basalt raw materials and with distinct production technologies. All presented basalt fiber types were studied before mixing with concrete and after it has cured. Size and morphology, young's modulus, tensile strength, bending modulus and flexural properties as well as chemical analysis tests were carried out on the types of basalt fibers under consideration. One type of basalt fibers showed better alkali resistance properties due to the special selection of raw materials for the basalt fibers production.
\end{abstract}

Keywords Basalt fibers · Basalt filaments · basalt fibers production · Mechanical properties · Alkali resistance $\cdot$ Fiberreinforced concrete

\section{Introduction}

Toughness, cracking capacity, ductility after cracking, flexural and impact strength, rheology and durability are some of the engineering challenges of concrete for various applications. Concrete is the main building material due to its abundance and cost compared to other materials. However, different applications require specific properties and may not be suitable for all types of applications. Adding fibers to the concrete mix can significantly improve the engineering properties of concrete, which can meet the requirements of various applications. According to previous studies $[11,18,20,28,31,40]$, the use of fibers also has some additional benefits such as reduced abrasive wear of concrete, which is mainly influenced by aggregate properties, environmental conditions, water-to-cement ratio, fiber volume in the mix, use of additives, voids, cement type and concrete mix proportions.

There are various types of fibers on the market for reinforcing cementitious composites, such as steel, organic, glass, asbestos and polypropylene fibers [13]. It is noticed that fiber-reinforced concrete (FRC) with high ductility, durability and corrosion resistance and high-performance fiber-reinforced concrete (HPFRC) are widely used in military, marine and civilian areas such as explosion-proof structures, offshore platforms, airport runways and highway pavements $[1,35,36]$.

Among all the currently used fibers, steel fibers stand out for their high modulus of elasticity and stiffness which help to improve the flexural strength of concrete [32].

Volodymyr Gulik, volodymyr.gulik@gmail.com | ${ }^{1}$ Institute of Physics, University of Tartu, W. Ostwaldi 1, 50411 Tartu, Estonia. ${ }^{2}$ OÜ BasaltEst, Sireli 3, 61506 Elva, Estonia. ${ }^{3}$ US Basalt Corporation, Richmond, TX 77407, USA. ${ }^{4}$ Institute for Safety Problems of Nuclear Power Plants, Lysogirska 12, Kyiv 03142, Ukraine. 
However, corrosion is a persisting problem when using steel fibers in concrete composite. Additionally, it has been observed that steel fibers, when added to the mix, cause a balling effect and workability of the concrete was significantly reduced [26]. Glass fibers are susceptible to alkaline environments, while the chemically inert carbon fiber has the distinct disadvantage of being expensive and anisotropic. On the other hand, synthetic fibers usually have low modulus of elasticity and low melting point.

Basalt fibers (BFs) are a good alternative to other type of fibers and offer the promising opportunities for innovative applications in concrete composite, due to their advantages such as high modulus of elasticity, high thermal stability, satisfactory chemical resistance, good sound insulation, high strength, good electrical properties and commercial availability, and all have been studied by number researchers over the past two decades $[4,7,8$, $10,12,15,19,24,30,31,42]$. It should also be noted that although the process for the production of basalt fiber is similar to the process for the production of fiberglass, it is much simpler, due to the fact that basalt is a so-called single-component raw material. This makes it cheaper than many types of glass fibers. In addition, the process of basalt fiber production is much more environmentally friendly than the production of other types of fibers $[4,8$, 23]. Basalt fiber production process is continuous, similar to the fiberglass production process [14], and it can be roughly divided into seven main stages: rock preparation, melting, fiber formation, coating, winding, drying and assembling, chopping or twisting.

Several studies have been carried out on basalt fibers as a strengthening material for concrete composites [1, $17,30]$. These studies were devoted to the impact of short basalt fiber strands on the properties of concrete. There is also an early study on the chemical resistance of basalt fibers by Ramachandran et al. [29]. This study can be considered as a basis for exploring the possibilities of using basalt fibers in reinforced concrete. In addition, [38] examined the physical and mechanical properties of a basalt fiberreinforced concrete composite after 28 days curing time and determined the optimal mixing amount of basalt fibers with cement paste. There have also been many studies on the relationship between basalt fibers mix amount and fracture toughness [9], impact behavior and damage evolution of basalt-FRC [37] and impact behavior of basalt fiber-reinforced concrete at various high strain rates [19]. There have also been other studies giving the community a better knowledge of the properties of basalt fiber to facilitate its use in concrete composites, such as the Brik study $[5,6]$ examining the properties of basalt fibers as a replacement for steel in concrete structures. Brik et al. [6] state that basalt fibers mix with concrete without segregation and does not form balls like steel fibers, so it is easier to handle during construction.

The reported research where concrete environment effects on the basalt fiber properties were observed was not considered in the context of choosing the right raw materials for the production of basalt fibers. This paper presents three types of basalt fibers from different manufacturers, which were produced from various basalt raw materials using distinct production technologies. All presented types of basalt fiber were investigated before mixing with concrete and after it has cured. Specimens were tested for dimensions and morphology, Young's modulus, tensile strength, bending modulus and flexural properties, as well as chemical resistance. The paper analyzes the test results from an engineering point of view in order to evaluate the performance of the samples in an alkaline environment and offer an appropriate chemical explanation. Physical test results, alone with chemical analysis, have provided insight into why one type of basalt fibers is superior to others inside concrete environment.

\section{Methods}

To simulate real production conditions, the fibers were mixed with fresh concrete from an Estonian commercial manufacturer (Rudus AS). There is a composition of the used concrete mixture in Table 1. A mixture of concrete and basalt fibers was poured into the mold. The prepared samples were stored for one month to ensure curing and to complete the chemical reactions between fibers and alkali. After that, samples of fiber-reinforced concrete
Table 1 The composition of concrete mixture for investigation

\begin{tabular}{|c|c|c|c|}
\hline Component & Type & Supplier & \\
\hline Cement & CEM II/B-M(T-L) 52,5 N & $\begin{array}{l}\text { AS Kunda Nordic Tsement (Heidelberg } \\
\text { Cement Group), Estonia }\end{array}$ & $330 \mathrm{~kg} / \mathrm{m}^{3}$ \\
\hline Coarse aggregate & $\begin{array}{l}\text { Gravel aggregate with } \\
\text { fraction size } 8 / 16 \mathrm{~mm}\end{array}$ & $\begin{array}{l}\text { AS Kunda Nordic Tsement local Aru-Lõuna } \\
\text { limestone quarry, Estonia }\end{array}$ & $850 \mathrm{~kg} / \mathrm{m}^{3}$ \\
\hline Fine aggregate & River sand & Rudus AS, Estonia & $1000 \mathrm{~kg} / \mathrm{m}^{3}$ \\
\hline Plasticizer & Acrylic superplasticizer & Product name: Dynamon XTend W300 N & $2 \mathrm{~kg} / \mathrm{m}^{3}$ \\
\hline Water & - & - & $200 \mathrm{~kg} / \mathrm{m}^{3}$ \\
\hline
\end{tabular}


were crushed and basalt fibers were collected for further analysis.

Basalt fibers selected for testing within present study had different geometry, mechanical and chemical properties, but they were all intended for use in concrete as crack control additives. Particular interest to the research group was the question of how the interaction of various types of basalt fibers with the chemical environment of concrete affects the physical and chemical properties of the fibers, as well as their behavior inside concrete samples.

For instance, type A fibers are made in large volume bath-type melting furnaces attached to a long forehearth with multiple bushings and winding apparatuses underneath. Such furnaces are known by high process stability and sufficient time to produce a homogeneous melt. The fibers obtained in such furnaces have typically minimal internal defects and demonstrate good mechanical strength. Furnaces for producing type B fibers are small, approximately one cubic meter of melt volume (one furnace one bushing/one winder as a rule) with almost no melt stabilization zone. Therefore, characterized type B fibers indicated significant number of internal defects and moderate mechanical properties. Type $C$ fibers are made in small melting furnaces with no fiber winding process. Therefore, type $C$ fibers differ by larger diameters and brittleness. Type $C$ fibers in contrast to fibers $A$ and $B$ are used mostly in concrete reinforcement application.

All samples of basalt fibers were tested twice: before and after interaction with the concrete matrix. That is, basalt fibers of the same origin were added to the concrete mixture, and after one month of curing, the fibers were extracted from the concrete and evaluated. The molded concrete bigger pieces were crushed to smaller ones. In many cases, half of the fiber was pulled out from the concrete matrix and bristled out from other part. By using optical microscope and tweezers, the basalt fibers were extracted from the matrix material. The structural and mechanical properties of considered basalt fiber samples were analyzed by a scanning electron microscope (SEM) and an atomic force microscope (AFM). SEM was used to measure the size, morphology and diameter as well as the tensile strength of the fibers. AFM was used to measure the surface roughness of the fibers. Young's modulus and tensile strength for each sample were obtained on a homemade tensile tester. Finally, all basalt fiber samples were analyzed using X-ray fluorescence (XRF) and X-ray diffraction techniques to reveal their chemical composition. The radial distribution of chemical elements for all fiber samples was analyzed using high-resolution scanning electron microscopy (HR-SEM) and energy-dispersive $\mathrm{X}$-ray microanalysis (EDX).

SEM (Vega-II SBU, TESCAN) was used to study the size and morphology of three different basalt fiber samples. In order to increase the conductivity of basalt fibers, which are inherently very good insulators, they were first coated with a gold/palladium film using a spray coater. The coating thickness was about $30 \mathrm{~nm}$. AFM was used to analyze the surface roughness of fibers (Dimension Edge, Bruker) in ambient conditions using cantilevers in the tapping mode (PPP-NCHR, Nanosensors).

Three different basalt fiber samples from each set were measured by tapping AFM. We selected $2 \times 2 \mu \mathrm{m}$ and $5 \times 5 \mu \mathrm{m}$ scan areas at two different locations on the fiber samples. A self-made tensile tester measured Young's modulus and tensile strength values. The tensile tester consists of a force transducer (TRI202PAD, Panlab) and a precision stage for high loads (M-413.3PD, Physik Instrumente). The force sensor has a measuring range of $50 \mu \mathrm{N}$ to $250 \mathrm{mN}$ with a resolution of $2 \mu \mathrm{N}$, and it has been calibrated using two weights $(0.2 \mathrm{~g}$ and $0.4 \mathrm{~g})$ that have been accurately measured in advance. Weights were attached to the force sensor, and the calibration measurements were repeated three times. The precision stage can move up to $300 \mathrm{~mm}$ with a minimum step size of $0.25 \mu \mathrm{m}$.

In tensile test, basalt filament was mechanically attached between the force sensor and fixed base by using clamps. Clamping length of filament (holding value inside clamps) was between 4.5 and $9.5 \mathrm{~mm}$ depending on obtained filament samples. Clamping length was measured with a precise digital caliper. Self-developed LabVIEW program was used to move automatically the precision stage and simultaneously record the force and the movement of the stage (deformation of the clamped filament). After the tensile test, the diameter for each sample was measured by SEM. Using the obtained results, the stress-strain curves were calculated and the linear part of the curve (slope) was used to find the Young's modulus $(E=\sigma / \varepsilon$ where $E$ is Young's modulus, $\sigma$ is stress and $\varepsilon$ is strain).

Randomly selected basalt fiber samples were mechanically placed in the clamps of the tester. The stretching length of the fiber samples was 7-20 mm. A force sensor and actuator were used to measure the applied load, and deformation of the samples and recorded by using a LabVIEW interface. Since the maximum load that could be measured with the tensile tester was about $30 \mathrm{~g}$, most of the type $A$ and type $B$ specimens and several of the type $C$ basalt specimens were broken during the measurement. The maximum stress just before breaking the fiber made it possible to determine the ultimate strength.

To measure the bending modulus of basalt fiber samples, the technique of bending a cantilever beam inside a scanning electron microscope was used. The basalt filaments were glued to the SEM stub with a vacuum compatible epoxy adhesive (2216 B/A, 3 M Scotch-Weld) causing the filament to protrude $1-3 \mathrm{~mm}$ beyond the edge of the 
stub. An AFM cantilever (RFESP, Veeco) was attached to a nanomanipulator (SLC-1720-S, SmarAct) and was used to bend filaments and simultaneously measure the applied force. The force applied during the bending process was calculated using a constant normal force $(3 \mathrm{~N} / \mathrm{m})$ and cantilever deflection. The latter was obtained by SEM imaging before bending (see Fig. 1a) and just before the AFM cantilever slipped off the basalt filament (see Fig. 1b). The bending modulus was calculated using the elastic beam theory.

$X$-ray diffractometry (XRD) and XRF spectrometry were used for chemical analysis of basalt fiber samples. XRD was measured on samples ground by hand with an agate mortar and pestle and prepared as non-oriented preparations. The measurements were carried out on a Bruker D8 Advance diffractometer using CuKa radiation and a Lynx-Eye detector in the 2 Theta $2-70^{\circ}$ range with a step of 0.017 . The chemical composition of basalt fiber samples was analyzed from pressed powder pellets using XRF on a Rigaku Primus II XRF spectrometer (Rigaku) using the basic parameter quantification model and the USGS BCR-2 reference basalt as standard. The samples were ground in a tungsten carbide (WC) ball mill.

High-resolution scanning electron microscopy (HRSEM) and energy-dispersive $X$-ray microanalysis were used to study the radial distribution of chemical elements in the basalt fiber samples. They were performed using a Helios Nanolab 600 scanning electron microscope (FEI Company) equipped with an EDX INCA Energy 350 analyzer (Oxford
Instruments). To obtain a cross section, the basalt filament bundles were fixed between aluminum plates using silver paste. After the paste hardened, the top of the filaments was mechanically broken by bending to expose a fresh surface. To make the sample conductive for HR-SEM studies, the basalt filaments were also coated with a thin layer of a mixture of $\mathrm{Pt}$ and $\mathrm{Au}$ using magnetron sputtering.

\section{Results and discussion}

\subsection{Size and morphology}

The size and morphology of all types of basalt fibers were studied before adding them to the concrete mixture, as well as after hardening and breaking of concrete. Twentyfive filaments of each type of basalt fiber were measured, and the average diameters were calculated. The results of measurements and calculations are presented in Table 2 . Thus, the average diameter of type $A$, type $B$ and type $C$ basalt filaments was $19.1 \pm 0.8 \mu \mathrm{m}, 23.6 \pm 1.2 \mu \mathrm{m}$ and $37.7 \pm 3.5 \mu \mathrm{m}$, respectively.

All types of basalt fiber samples were highly homogeneous and mostly had a smooth surface. Upon closer examination of the basalt filament, it was found that some of the fibers had small particles and irregularities on the surface. Type A filaments had a fairly smooth surface with irregular oval areas (see Fig. 2b), and some of the filaments
Fig. 1 SEM images of bending BF filament using AFM cantilever inside SEM
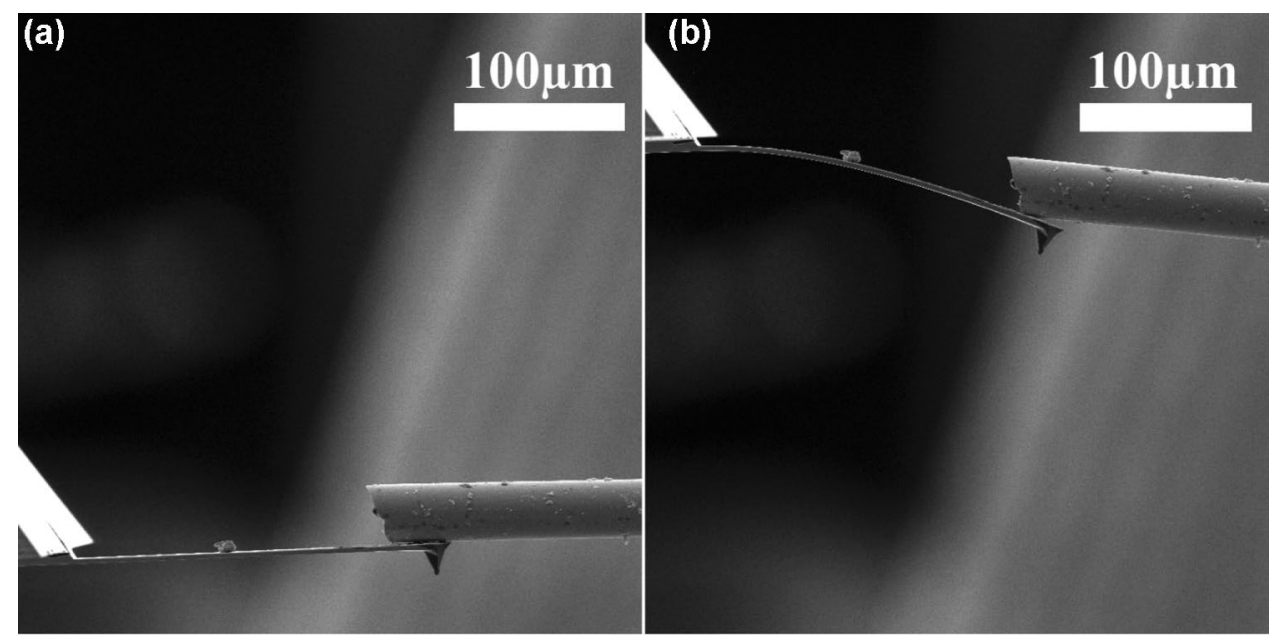

Table 2 Summarized table of structural and mechanical properties of three different types of BF samples

\begin{tabular}{llllll}
\hline Fibers & Diameter, $\mu \mathrm{m}$ & $\begin{array}{l}\text { Surface rough- } \\
\text { ness, } \mathrm{nm}\end{array}$ & $\begin{array}{l}\text { Young's modu- } \\
\text { lus, GPa }\end{array}$ & $\begin{array}{l}\text { Tensile strength, Bending } \\
\mathrm{MPa}\end{array}$ & $\begin{array}{l}\text { Bedulus, } \\
\text { moda } \\
\mathrm{GPa}\end{array}$ \\
\hline Type A & $19.1 \pm 0.8$ & $1.8 \pm 0.2$ & $53.0 \pm 4.6$ & $588 \pm 92$ & $63.1 \pm 5.9$ \\
Type B & $23.6 \pm 1.2$ & $2.5 \pm 0.5$ & $51.9 \pm 5.0$ & $542 \pm 78$ & $50.3 \pm 7.8$ \\
Type C & $37.7 \pm 3.5$ & $1.5 \pm 0.3$ & $19.9 \pm 3.6$ & $309 \pm 52$ & $40.7 \pm 3.3$ \\
\hline
\end{tabular}


Fig. 2 SEM images of type A basalt filaments before concrete mixture

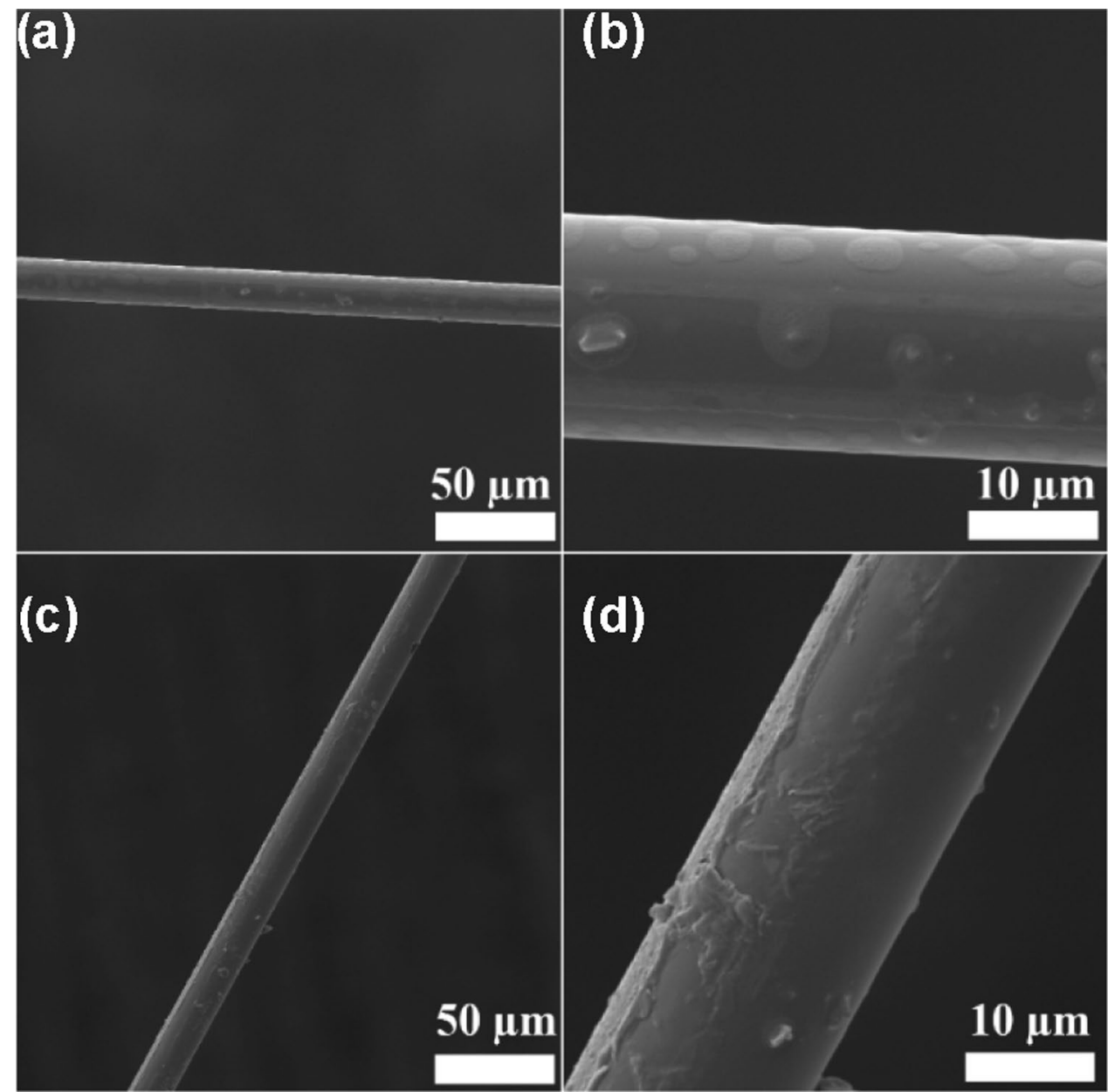

had a pronounced surface structure (see Fig. 2d). Likewise, most type B filaments had a smooth surface with irregular oval spots (see Fig. 3b, d), with some of the filaments having a fairly large surface contamination (see Fig. 3b). SEM images of type $C$ filaments revealed the smoothest surfaces of the three samples with fewer fine particles (Fig. 4).

\subsection{Surface roughness}

Surface roughness of all types of basalt fibers was studied before adding them to the concrete mixture, as well as after hardening and breaking of concrete. Surface roughness was measured using an AFM (Dimension Edge, Bruker). AFM images and line profiles for different basalt fiber samples before they were added to concrete mix are presented in Figs. 5, 6, 7.

The AFM surface roughness measurements were carried out simultaneously with the SEM inspection. All filaments showed very low surface roughness, especially type $C$, which had the lowest value. The average surface roughness values were $1.8 \pm 0.2,2.5 \pm 0.5$ and $1.5 \pm 0.3 \mathrm{~nm}$ for the basal filament samples of type $A$, type $B$ and type $C$, respectively.

AFM images of two type A basalt filaments with linear surface profiles are presented in Fig. 5. The line profiles were used to calculate the average surface roughness. It can be seen from the images and line profiles that the surface of the filaments is mostly flat, with many small particles and a few large ones. The particle height remains in the range of 10-40 $\mathrm{nm}$. AFM images of type $B$ basalt filaments are shown in Fig. 6. The surface of filaments is usually smooth, with few small particles. Type $B$ basalt filaments exhibit large-scale surface structures that can be seen on AFM (Fig. 6b) and SEM (Fig. 3b) images. Figure 7 presents AFM images of two basalt filaments of type $C$. Although the AFM images show some particles on the surface of the C-type basalt filaments, it can be seen from the line profile that the size and height of these particles are very small and therefore have a low surface roughness. 
Fig. 3 SEM images of type $B$ basalt filaments before concrete mixture

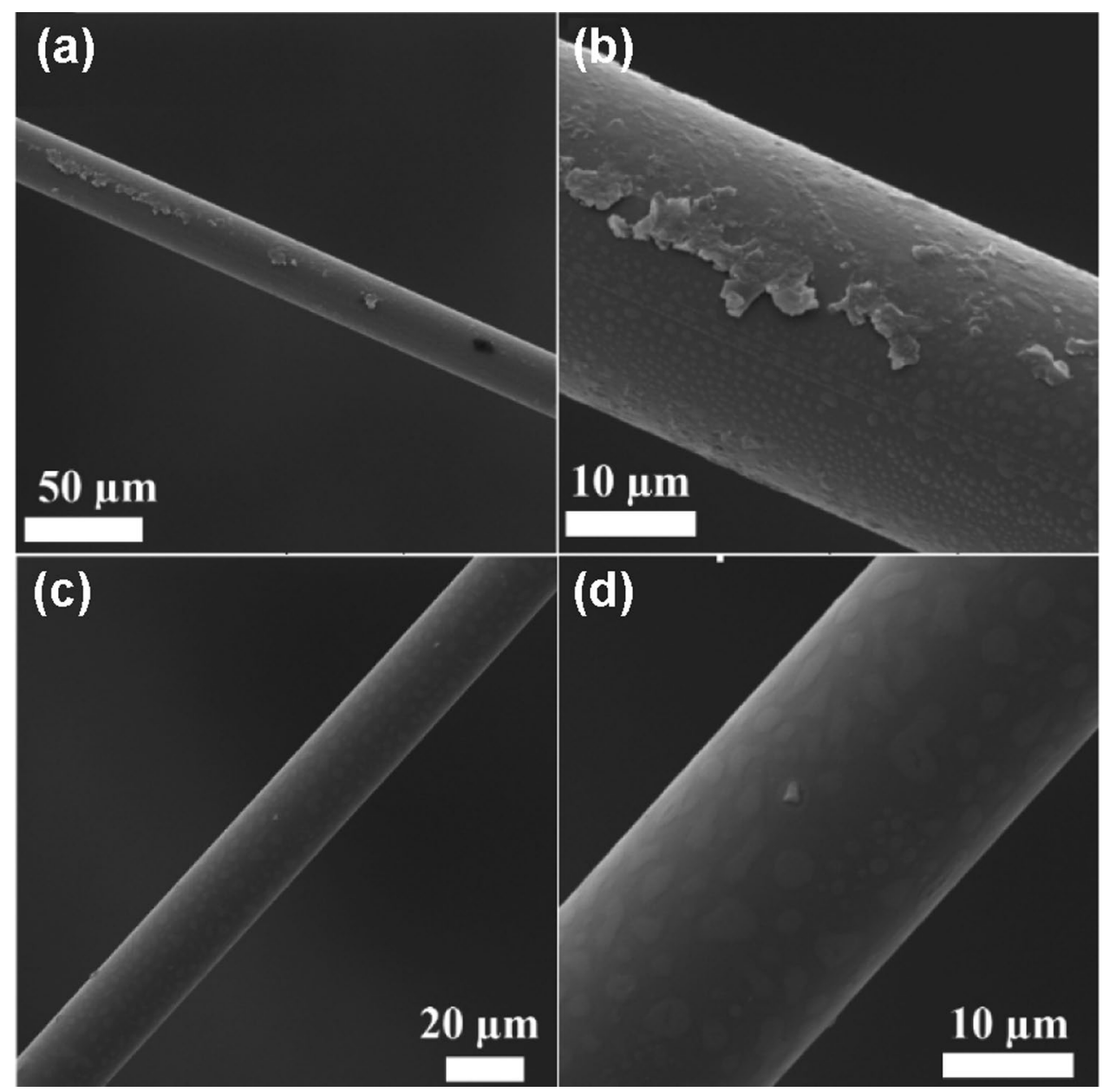

\subsection{Young's modulus and tensile strength}

Fifteen filaments of each fiber type were measured. Type A showed the highest Young's modulus of $53.0 \pm 4.6 \mathrm{GPa}$ and tensile strength of $588 \pm 92 \mathrm{MPa}$. Type B filaments were fairly close to type $A$, with Young's modulus of $51.9 \pm 5.0 \mathrm{GPa}$ and tensile strength of $542 \pm 78 \mathrm{MPa}$. The smallest values were obtained for type $C$ filaments with Young's modulus $19.9 \pm 3.6 \mathrm{GPa}$ and tensile strength of $309 \pm 52 \mathrm{MPa}$. The stress-strain curves were mostly linear and the filaments suddenly broke without significant deformation, which is normal behavior for glass-like materials.

\subsection{Bending modulus and flexural properties}

A total of 10 strands of each fiber type were tested for the bending modulus. As shown in Table 2, the bending modulus follows the same trend as Young's modulus. Type A filaments show the highest values and type $C$ filaments the lowest. In numbers, the bending modulus averaged $63.1 \pm 5.9 \mathrm{GPa}, 50.3 \pm 7.8 \mathrm{GPa}$ and $40.7 \pm 3.3 \mathrm{GPa}$ for type $A$, type $B$ and type $C$ filaments, respectively. As you can see, the values of the bending modulus for the type $\mathrm{A}$ and $\mathrm{C}$ filaments are slightly higher than their Young's modulus. This is typical for heterogeneous and anisotropic materials, where the two values do not match. The bending modulus mainly depends on the area of the surface that is subjected to the greatest stress. Surface stiffness combined with surface defects such as pores, cracks and surface contamination (or lack thereof) can affect the flexural modulus.

Further bending tests of the same basalt filaments inside the SEM were used to qualitatively evaluate their bending properties. Several bending tests were carried out for each type of basalt filament using the cantilever part of the AFM tip. During measurements, all tested samples showed high elasticity and high fracture resistance. The filaments can be bent over 180 degrees without breaking and broke only when they were bent very close (100-200 microns) to the part they were bonded. 
Fig. 4 SEM images of type $C$ basalt filaments before concrete mixture
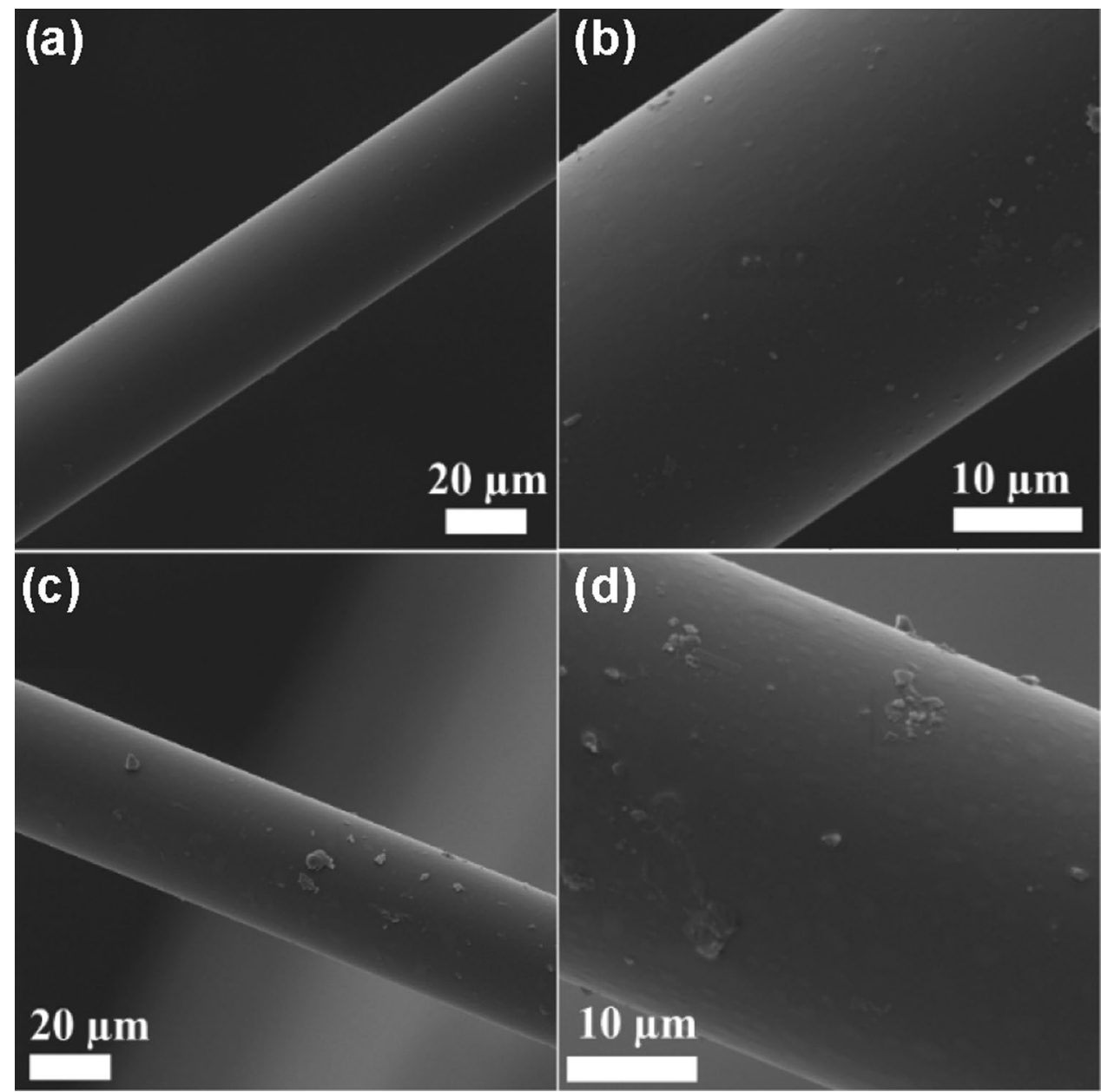

\subsection{The mechanical properties of basalt fiber samples after concrete medium}

The mechanical properties of basalt filaments extracted from hardened concrete, such as their size and morphology, surface roughness, Young's modulus, ultimate strength and bending modulus, are presented in Table 3 . Table 4 shows the relative changes in the mechanical properties of basalt fibers after their interaction with concrete.

As can be seen from Tables 2, 3, 4, there is a significant decrease in the mechanical characteristics of type $A$ and type $B$ basalt fibers, for example, a decrease in diameter by $2-5 \%$; reduction of surface roughness by $57 \%$; decrease in Young's modulus by $31-37 \%$; decrease in tensile strength by $25-29 \%$; and reduction of the bending modulus by $17-21 \%$. However, it was noted that there was no significant decrease in diameter, Young's modulus and flexural modulus for type $C$ basalt fiber. This can be explained by the different chemical composition of basalt rock, which is the main material for the production of basalt fibers. Type $\mathrm{C}$ uses so-called alkaline basalts. The chemical composition of all tested types of basalt was analyzed and discussed in chapter 3.6. It should also be noted that type $C$ basalt filaments have the largest diameter compared to others tested in this study.

SEM images of types A, B and C basalt filaments after their interaction with concrete are shown in Figs. 8, 9 and 10 , respectively.

SEM images showed that some of the filaments were fairly clean and had a smooth surface. At the same time, some of the filaments had a thin layer of concrete on them (about several hundred $\mathrm{nm}$ thick). The type $A$ specimens were the "cleanest" with fewer filaments covered with concrete. Type $C$ had the thickest concrete layer with many fully coated filaments. To be able to compare the surface roughness of the fibers before and after interaction with the concrete matrix, the only fibers that did not have a concrete cover were selected for AFM analysis. The results show that type $C$ had the highest adhesion to concrete.

The AFM images of type $A$, type $B$ and type $C$ basalt filaments extracted from concrete are presented in Figs. 11, 12,13 , respectively. 

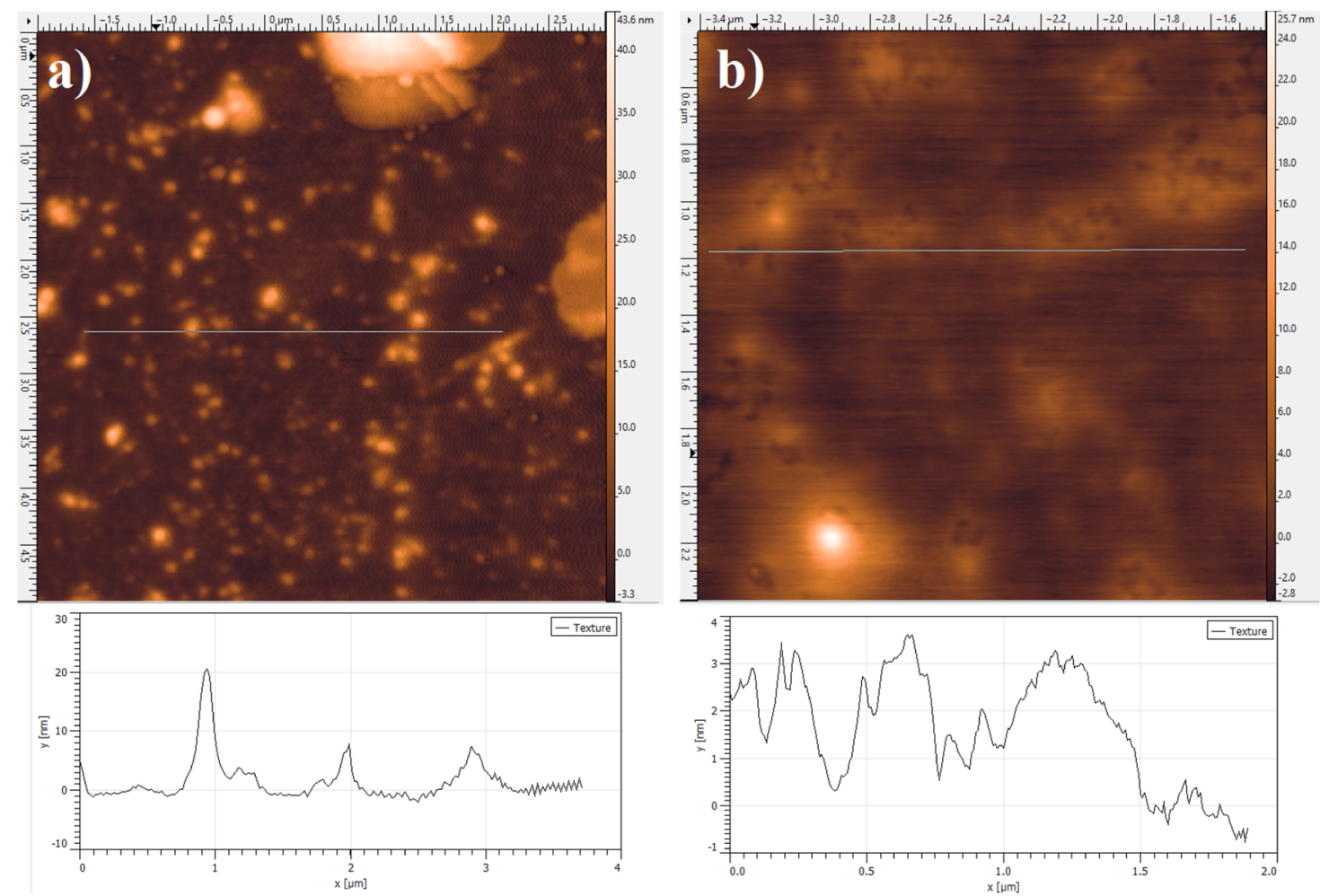

Fig. 5 AFM images and line profile of type A basalt filament before concrete mixture surface with scanning area of a $5 \times 5 \mu \mathrm{m}$ and $\mathbf{b} 2 \times 2 \mu \mathrm{m}$

Fig. 6 AFM images and line profile of type B basalt filament before concrete mixture surface with scanning area of a $3 \times 3 \mu \mathrm{m}$ and $\mathbf{b} 5 \times 5 \mu \mathrm{m}$
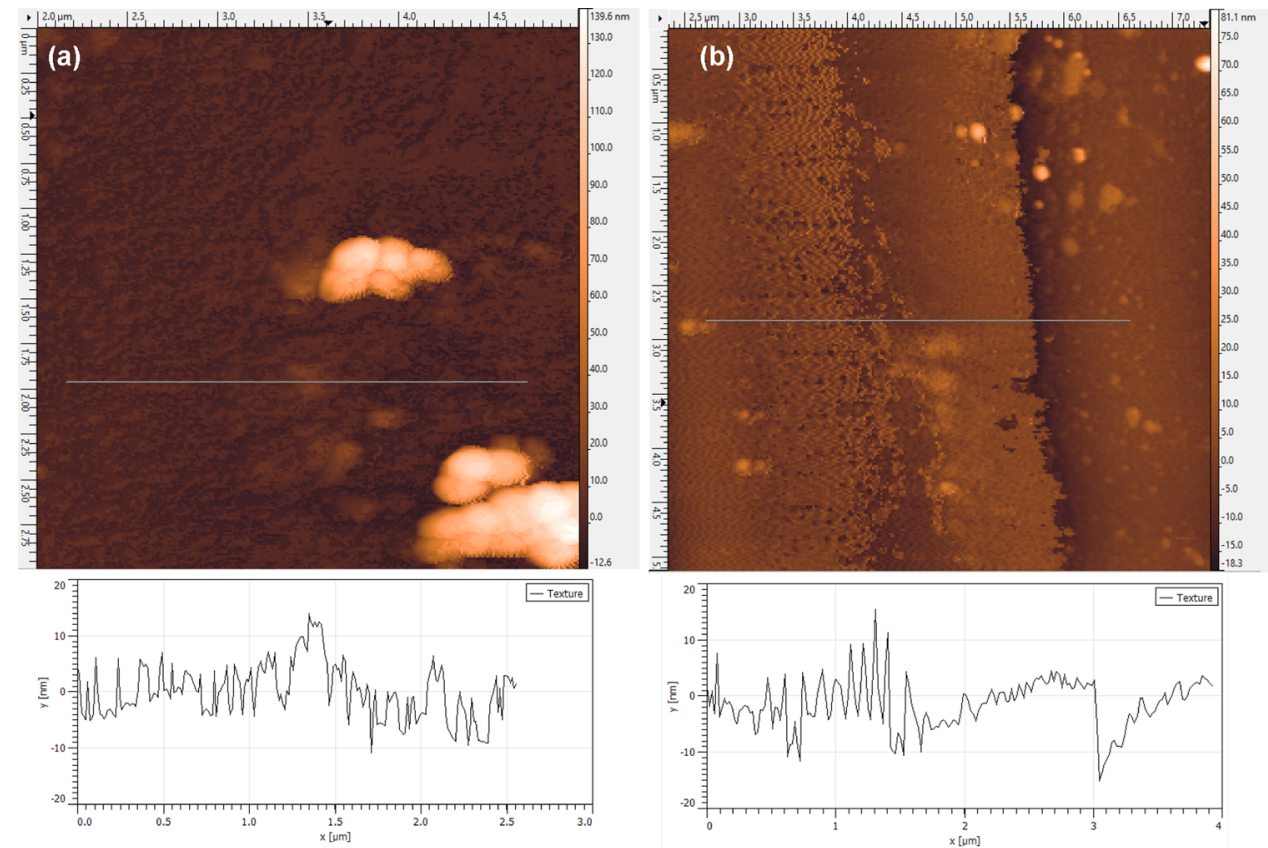

\subsection{Chemical analysis}

There have been relatively few systematic studies about dependency of the chemical and mechanical properties on the basalt fiber's chemical compositions or research of the initial raw materials [22], while at the same time, the very fact of such influence is generally recognized in community of basalt fiber producers.

\section{SN Applied Sciences}



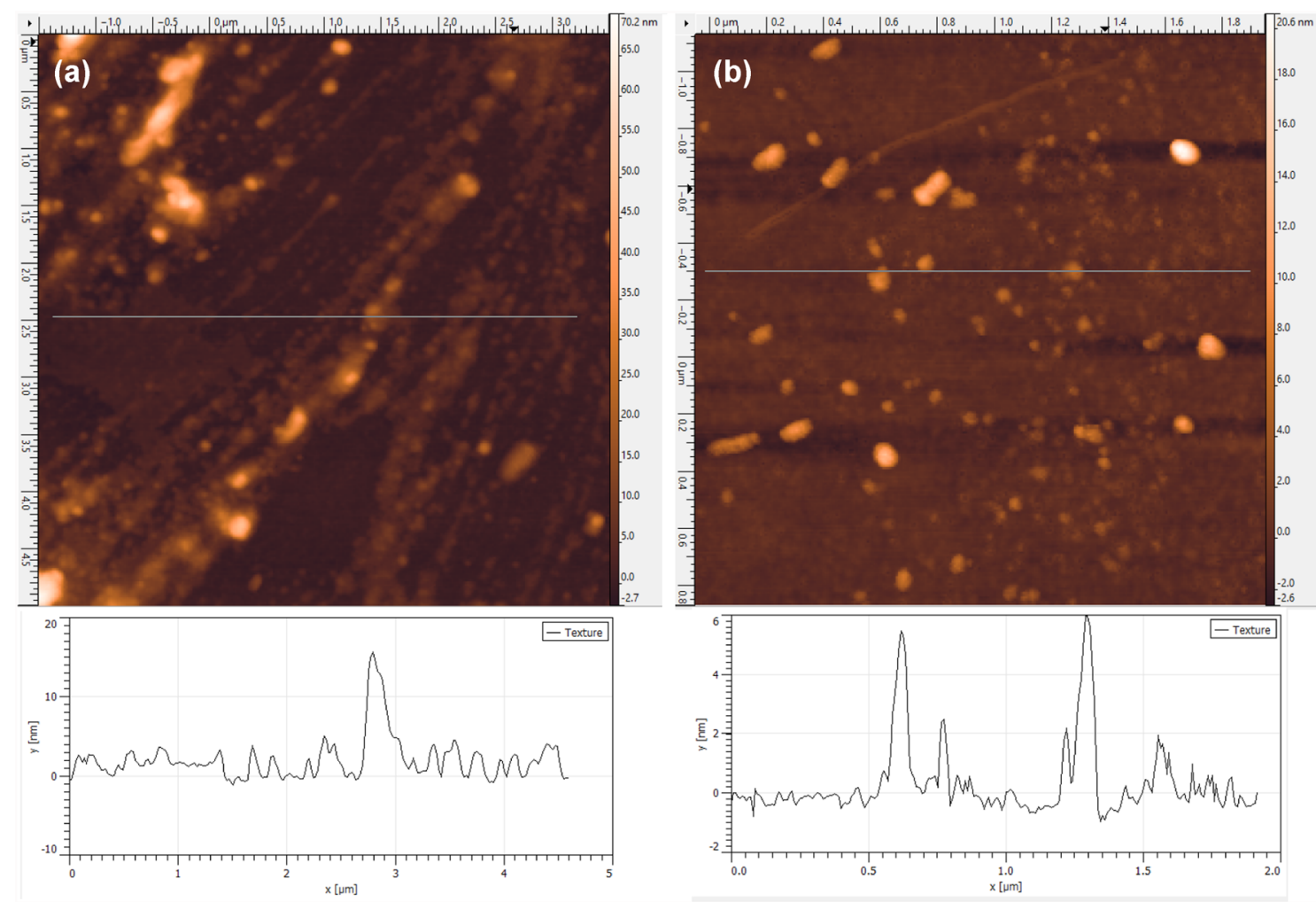

Fig. 7 AFM images and line profile of type $C$ basalt filament before concrete mixture surface with scanning area of a $5 \times 5 \mu \mathrm{m}$ and $\mathbf{b} 2 \times 2 \mu \mathrm{m}$

Table 3 Summarized table of structural and mechanical properties of three different types of basalt filaments samples after concrete environment (alkaline medium)

Table 4 Summarized table of relative changes for structural and mechanical properties of three different basalt filaments samples after concrete environment (alkaline medium)

\begin{tabular}{llllll}
\hline Fibers & Diameter, $\mu \mathrm{m}$ & $\begin{array}{l}\text { Surface rough- } \\
\text { ness, } \mathrm{nm}\end{array}$ & $\begin{array}{l}\text { Young's modu- } \\
\text { lus, GPa }\end{array}$ & $\begin{array}{l}\text { Tensile strength, } \\
\mathrm{MPa}\end{array}$ & $\begin{array}{l}\text { Bending } \\
\text { modulus, } \\
\text { GPa }\end{array}$ \\
\hline Type A & $18.1 \pm 0.8$ & $4.1 \pm 1.0$ & $36.3 \pm 3.8$ & $417 \pm 55$ & $49.5 \pm 4.0$ \\
Type B & $23.2 \pm 1.4$ & $5.9 \pm 0.6$ & $32.8 \pm 4.7$ & $406 \pm 71$ & $41.5 \pm 4.2$ \\
Type C & $37.7 \pm 1.2$ & $6.1 \pm 0.6$ & $24.9 \pm 3.0$ & $242 \pm 50$ & $40.1 \pm 5.0$ \\
\hline
\end{tabular}

\begin{tabular}{lllllr}
\hline Fibers & Diameter, $\mu \mathrm{m}$ & $\begin{array}{l}\text { Surface rough- } \\
\text { ness, } \mathrm{nm}\end{array}$ & $\begin{array}{l}\text { Young's modu- } \\
\text { lus, GPa }\end{array}$ & $\begin{array}{l}\text { Tensile strength, } \\
\mathrm{MPa}\end{array}$ & $\begin{array}{l}\text { Bending } \\
\text { modulus, } \\
\mathrm{GPa}\end{array}$ \\
\hline Type A & $-5.23 \%$ & $+56.3 \%$ & $-31.51 \%$ & $-29.08 \%$ & $-21.55 \%$ \\
Type B & $-1.69 \%$ & $+57.3 \%$ & $-36.8 \%$ & $-25.09 \%$ & $-17.49 \%$ \\
Type C & $0 \%$ & $+76.2 \%$ & $+20.08 \%$ & $-21.68 \%$ & $-1.47 \%$ \\
\hline
\end{tabular}

Considering that the chemical and mechanical properties of basalt fibers depend on the diameter of fibers, surface coatings and additives [41], as well as on the chemical compositions of the constituent fibers, there was carried out chemical analysis of all 3 types of fibers to determine the origin of degradation changes within geometric structure and the mechanical properties of presented basalt fiber types in an alkaline environment of the concrete.
Chemically basalt fiber structure is nearly related to E-glass fiber. The most important components of basalt fiber are $\mathrm{SiO}_{2}, \mathrm{Al}_{2} \mathrm{O}_{3}, \mathrm{Fe}_{2} \mathrm{O}_{3}, \mathrm{CaO}$ and $\mathrm{MgO}$ [2]. It could be noted that tensile strength and heat resistance of basalt fiber samples can be improved by increasing the content of $\mathrm{SiO}_{2}$ and $\mathrm{Al}_{2} \mathrm{O}_{3}$ [22].

Chemical compositions of three types of basalt fibers are presented in Table 5. Table 5 shows that silicon dioxide 
Fig. 8 SEM images of type $A$ basalt filaments after concrete environment
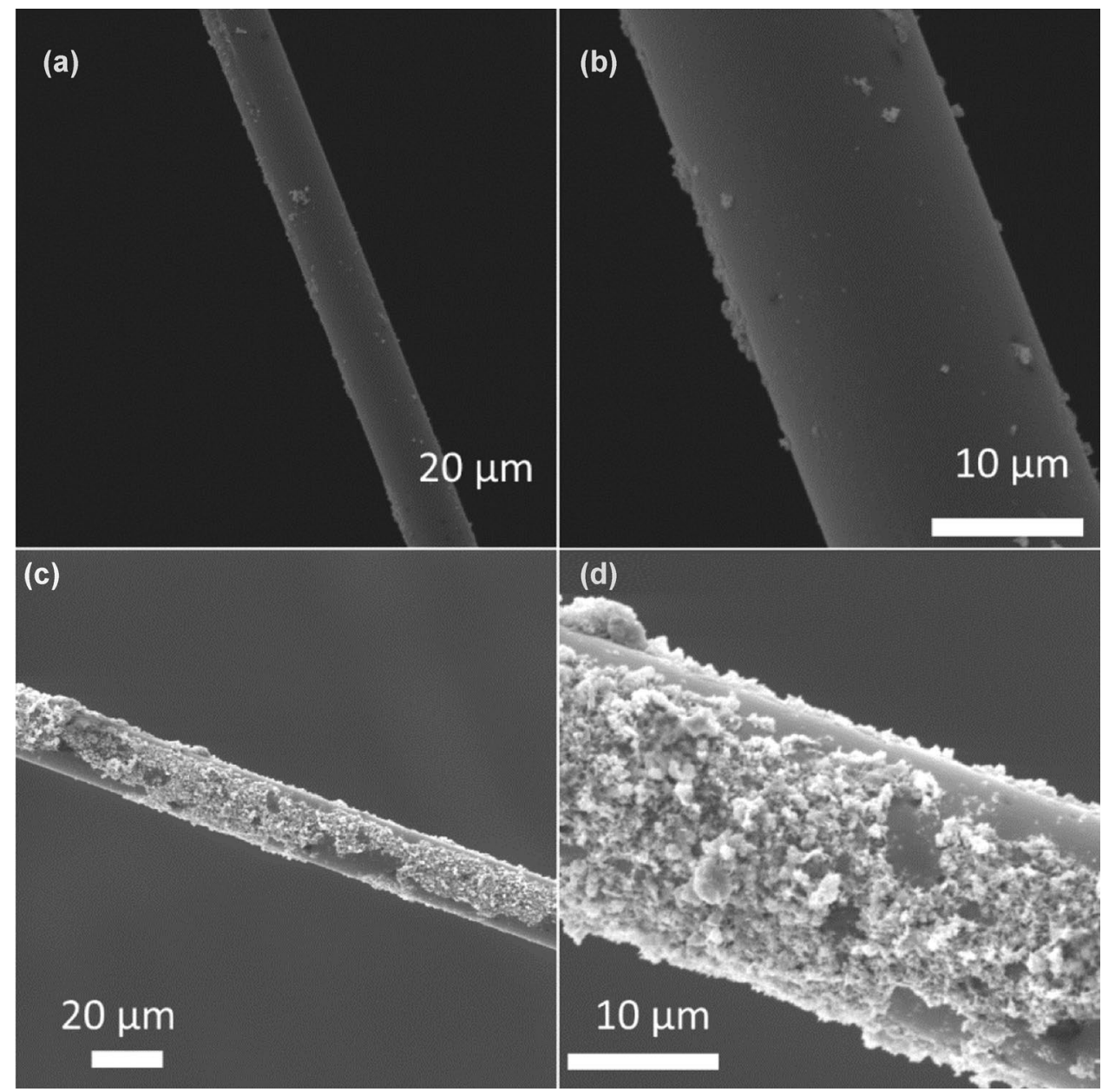

$\left(\mathrm{SiO}_{2}\right)$ predominates in all three samples: Type $A$ has $51.6 \%$; type $B$ has $52.5 \%$; and type $C$ has $47.4 \%$. It is worth noting that the content of silicon oxide in the sample of types $A$ and $B$ is approximately the same (presumably they use basalt raw materials from the same deposit), just as the content of silicon oxide in the type C samples is $8-10 \%$ lower. A lower silica content in the fiber could mean less fiber degradation in the concrete alkaline environment due to alkali-silica reaction. We also can see significant differences in aluminum oxide $\left(\mathrm{Al}_{2} \mathrm{O}_{3}\right)$ content: Type $\mathrm{A}$ has $14.9 \%$; type $\mathrm{B}-15.2 \%$; and type $\mathrm{C}-11.5 \%$. In case of aluminum oxide, there is an even greater difference between samples A, B and sample C, approximately 23-24\%. As for the iron oxide, Jigiris and Mahova [16] noted that calcium, magnesium and iron oxides have a positive effect on the durability of the basalt fibers.

Table 5 displays a fairly significant difference in iron oxide between types $A, B$ and type $C$ : type $A-12.6 \%$; type $B-11.6 \%$; and type $C-16.7 \%$. With regard to chemical composition analysis of degraded basalt fibers, Tang et al. [34] studied the alkali resistance of basalt fibers in sodium hydroxide $(\mathrm{NaOH})$ solution, and they noted that the presence of $\mathrm{TiO}_{2}, \mathrm{MnO}, \mathrm{Fe}_{2} \mathrm{O}_{3}$ and $\mathrm{Al}_{2} \mathrm{O}_{3}$ is slowing alkaline corrosion.

\subsection{SEM analysis of radial distribution of chemicals composition}

As reported in a study [21], basalt fiber with 5.7 wt\% $\mathrm{ZrO} 2$ had better alkali resistance properties due to the formation of a protective surface layer with an improved chemical composition on the fibers. We made an attempt to study the distribution of chemical elements over the radial section of the basalt filament in order to determine the possible displacement of metal oxides from the fiber center to the periphery. (This could explain the increase in the resistance of the C-type basalt filament in the alkaline environment of concrete.) As noted in Sect. 2, HR-SEM and EDX were used for these studies.

The HR-SEM images of type A basalt filaments from concrete are presented in Fig. 14. The HR-SEM images of type $B$ basalt filaments from concrete are presented in Fig. 15. The HR-SEM images of type $C$ basalt filaments from concrete are presented in Fig. 16. All these figures show chemical

\section{SN Applied Sciences


Fig. 9 SEM images of type B basalt filaments after concrete environment
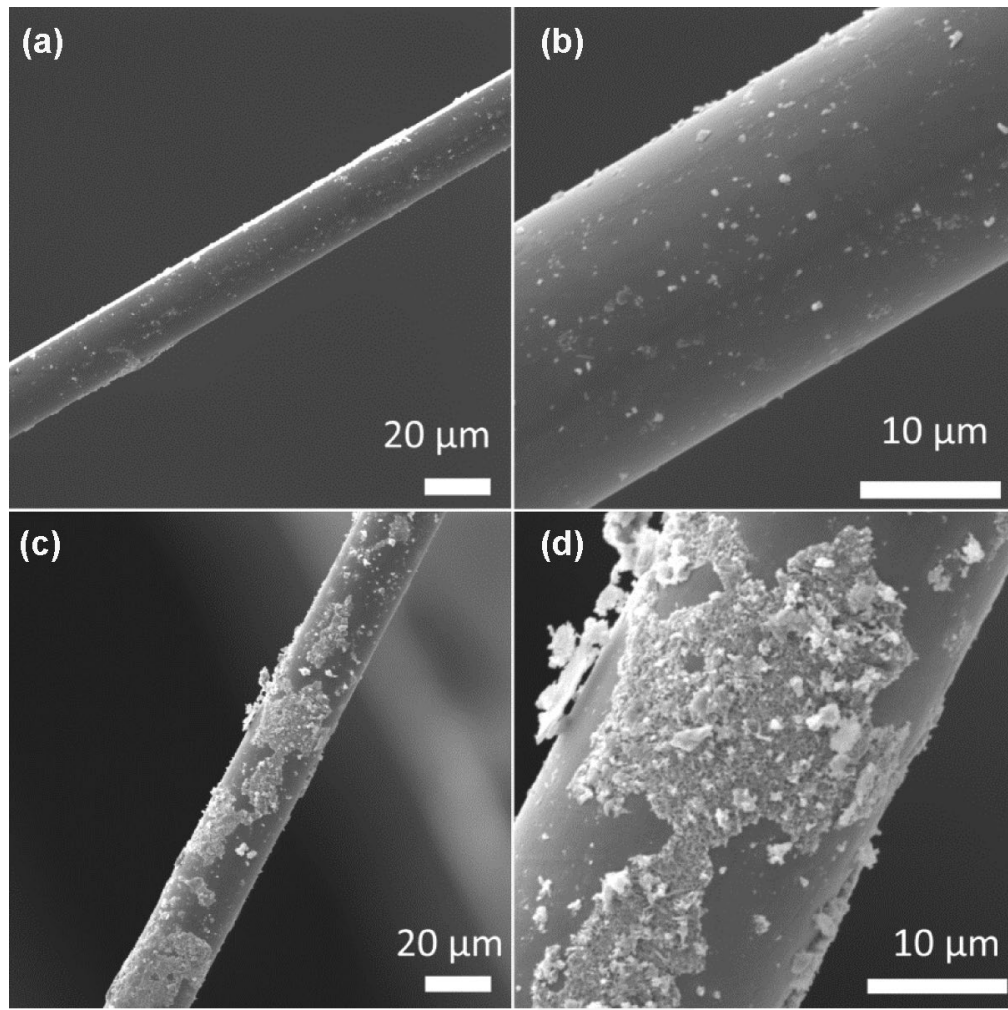

elements distribution over the basalt filaments radial cross section for the major chemical elements that may affect resistance of fibers in the alkaline environment of concrete.

Obtained results indicate no concentration variances over the cross-sectional area of the fiber for any of the measured element. With given experimental uncertainties, concentration variations lower than $5-10 \%$ could not be detected for any fiber type nor for any element. Thus, if there are concentration variances, these do not exceed the uncertainty levels.

\subsection{Discussion of obtained results}

All three types of basalt fiber samples were obtained from various basalt roving manufacturers who cut the roving into shorter strands $(10-25 \mathrm{~cm})$ so that they could be used as concrete additives.

As can be seen from the results obtained, there is a significant degradation of the geometry of the fibers and their mechanical properties after interaction with a concrete matrix for 28 days, especially in fibers of types A and B. As noted in the studies of Zimin and Tatarintseva [39] the chemical resistance of basalt fibers depends on the content of metal oxides in the glass and their ratio. Alkali and alkaline earth metal oxides especially affect fiber's durability. This explains to some extent the lower degradation of type $C$ fibers, where the alkali metal oxide content is $30 \%$ less than types
$A$ and $B$ fibers. Unfortunately, within present study it was not possible to verify the content of the chemical composition of basalt fibers after their interaction with a concrete matrix; therefore, we were unable to trace the degree of influence of the concrete environment on the chemical composition of the fiber. This aspect is the subject of future research, as well as observing chemical composition changes of basalt fibers in concrete matrix beyond horizon of 28 days (e.g., 90 days or 180 days of interaction).

A significant increase in the elastic modulus with a simultaneous decrease in the tensile strength and bending modulus of type $C$ fibers after their interaction with concrete is unexpectedly anomalous. Most likely, the measurement accuracy was influenced by the presence of a sufficiently thick concrete film covering the fiber surface.

According to Bentur and Mindess [3], fibers for the construction industry (different types of fibers, e.g., steel fiber, polypropylene fiber, basalt fiber, etc.) are commonly used as: (a) primary reinforcement for thin-sheet concrete components in which conventional reinforcing bars cannot be used [33], [25] and (b) secondary reinforcement to ensure ductility after cracking and for better crack control. The fibers presented in this study are used for secondary reinforcement. Since they are not designed to increase the strength of the concrete structure, their resistance to the alkaline environment of concrete is more important than mechanical strength. 
Fig. 10 SEM images of type $C$ basalt filaments after concrete environment

Fig. 11 AFM images and line profiles of type A basalt filament surface from concrete mixture with scanning area of a $2 \times 2 \mu \mathrm{m}$ and b $5 \times 5 \mu \mathrm{m}$
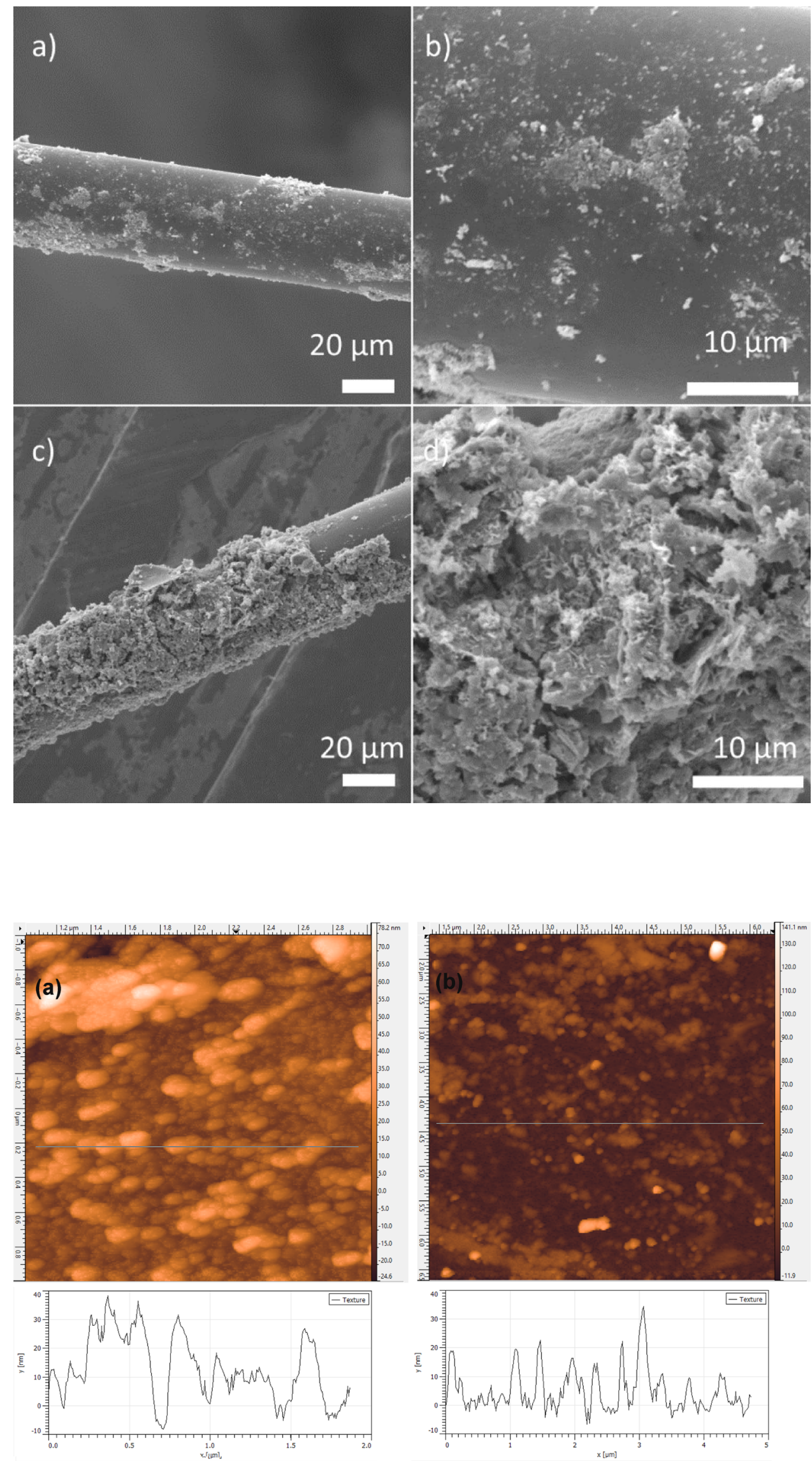
Fig. 12 AFM images and line profile of type $B$ basalt filament surface from concrete mixture with scanning area of a $5 \times 5 \mu \mathrm{m}$ and $\mathbf{b} 5 \times 5 \mu \mathrm{m}$
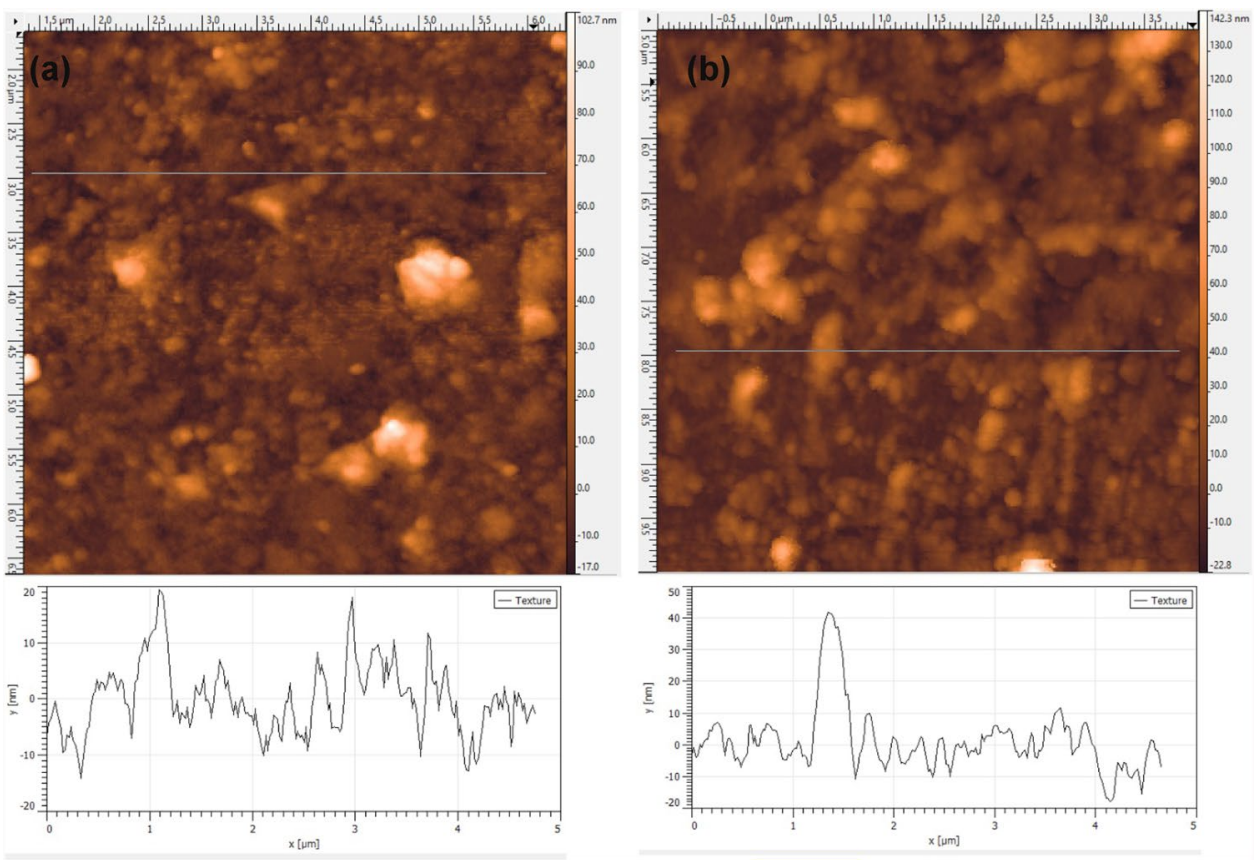

Fig. 13 AFM images and line profile of type $C$ basalt filament surface from concrete mixture with scanning area of a $1.5 \times 1.5 \mu \mathrm{m}$ and b $5 \times 5 \mu \mathrm{m}$
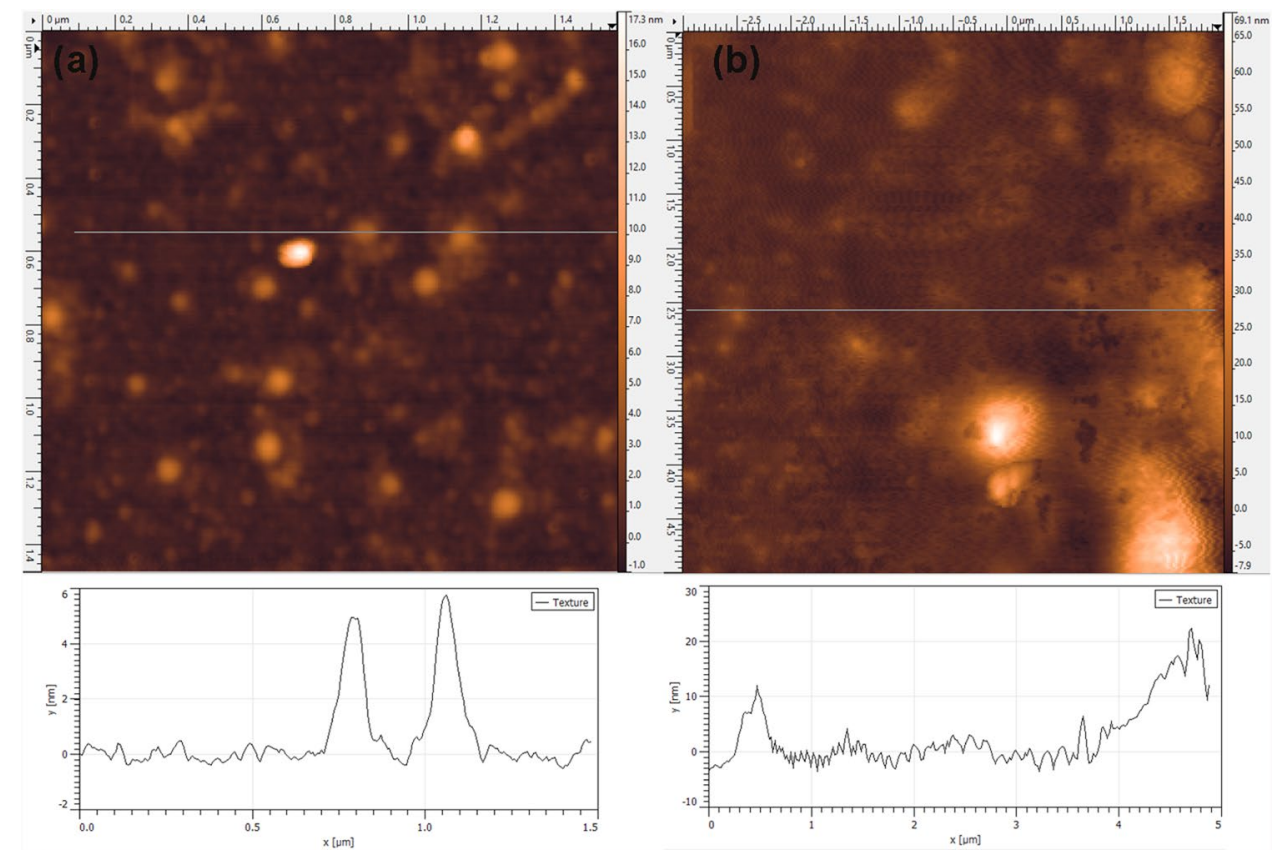

It should be noted that active research on the selection of raw materials for alkali-resistant basalt fibers was carried out by Novitski and Efremov [27], which is quite unusual for producers of basalt roving, who usually prefer to work with only one basalt quarry and leave consumers no choice.

\section{Conclusions}

Three types of basalt fibers from different manufacturers were studied from an engineering point of view to evaluate the performance of selected samples in an alkaline 
Table 5 Chemical compositions of three different BF types

\begin{tabular}{|c|c|c|c|c|c|c|}
\hline \multirow[b]{2}{*}{ Component } & \multicolumn{3}{|c|}{ Content (\% wt) } & \multicolumn{3}{|c|}{ Comparison of different BF types } \\
\hline & Type A & Type B & Type C & Type C/Type A & Type C/Type B & Type B/Type A \\
\hline $\mathrm{SiO}_{2}$ & 51.6 & 52.5 & 47.4 & $-8 \%$ & $-10 \%$ & $2 \%$ \\
\hline $\mathrm{Al}_{2} \mathrm{O}_{3}$ & 14.9 & 15.2 & 11.5 & $-23 \%$ & $-24 \%$ & $2 \%$ \\
\hline $\mathrm{TiO}_{2}$ & 1.3 & 1.2 & 2.9 & $124 \%$ & $144 \%$ & $-8 \%$ \\
\hline $\mathrm{Fe}_{2} \mathrm{O}_{3}$ & 12.6 & 11.6 & 16.7 & $33 \%$ & $44 \%$ & $-8 \%$ \\
\hline $\mathrm{MnO}$ & 0.2 & 0.2 & 0.3 & $43 \%$ & $61 \%$ & $-11 \%$ \\
\hline $\mathrm{CaO}$ & 9.0 & 8.6 & 9.6 & $6 \%$ & $11 \%$ & $-4 \%$ \\
\hline $\mathrm{MgO}$ & 6.0 & 6.3 & 7.9 & $32 \%$ & $26 \%$ & $5 \%$ \\
\hline $\mathrm{Na}_{2} \mathrm{O}$ & 1.9 & 1.9 & 1.8 & $-3 \%$ & $-4 \%$ & $2 \%$ \\
\hline $\mathrm{K}_{2} \mathrm{O}$ & 1.6 & 1.6 & 0.6 & $-63 \%$ & $-62 \%$ & $-2 \%$ \\
\hline $\mathrm{P}_{2} \mathrm{O}_{5}$ & 0.1 & 0.1 & 0.2 & $96 \%$ & $84 \%$ & $7 \%$ \\
\hline Stot & 0.002 & 0.003 & 0.002 & $0 \%$ & $-3 \%$ & $50 \%$ \\
\hline $\mathrm{Cl}$ & 0.011 & 0.010 & 0.005 & $-55 \%$ & $-50 \%$ & $-9 \%$ \\
\hline LOI950 & 0.00 & 0.00 & -0.01 & & & \\
\hline B & 0.6 & 0.7 & 0.8 & $33 \%$ & $14 \%$ & $17 \%$ \\
\hline
\end{tabular}
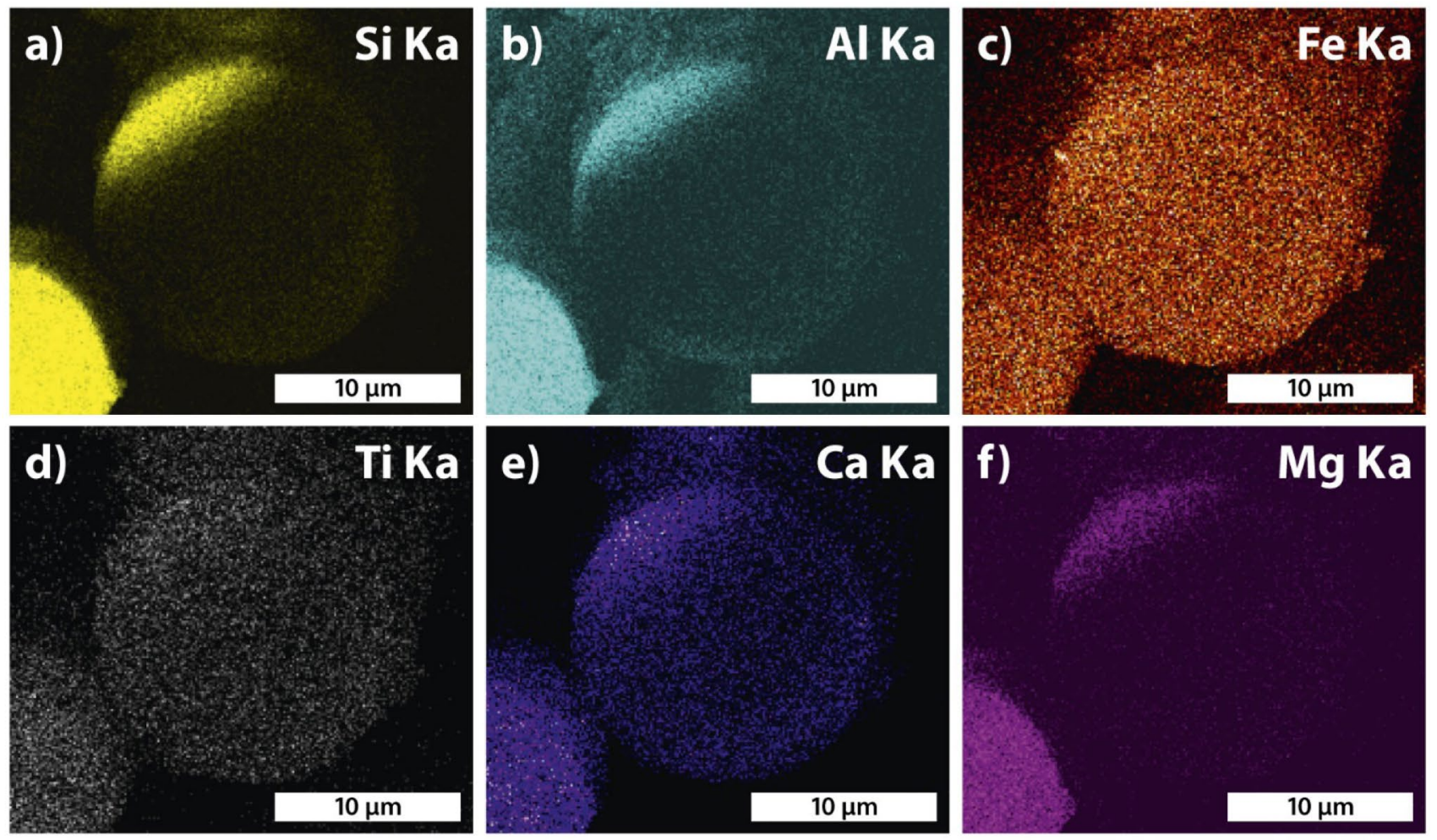

Fig. 14 HR-SEM images of chemical elements distribution over the BF radial cross section for type A basalt filaments

concrete environment. All types of fibers presented in this study were produced from different basalt raw materials and using different production technologies. Based on the above studies and analysis, several conclusions can be drawn.
- All fibers of basalt nature, regardless of raw materials and production technology, are subject to destruction in the alkaline environment of concrete;

- The chemical composition and diameter of basalt fibers have a great influence on the level of resistance of 

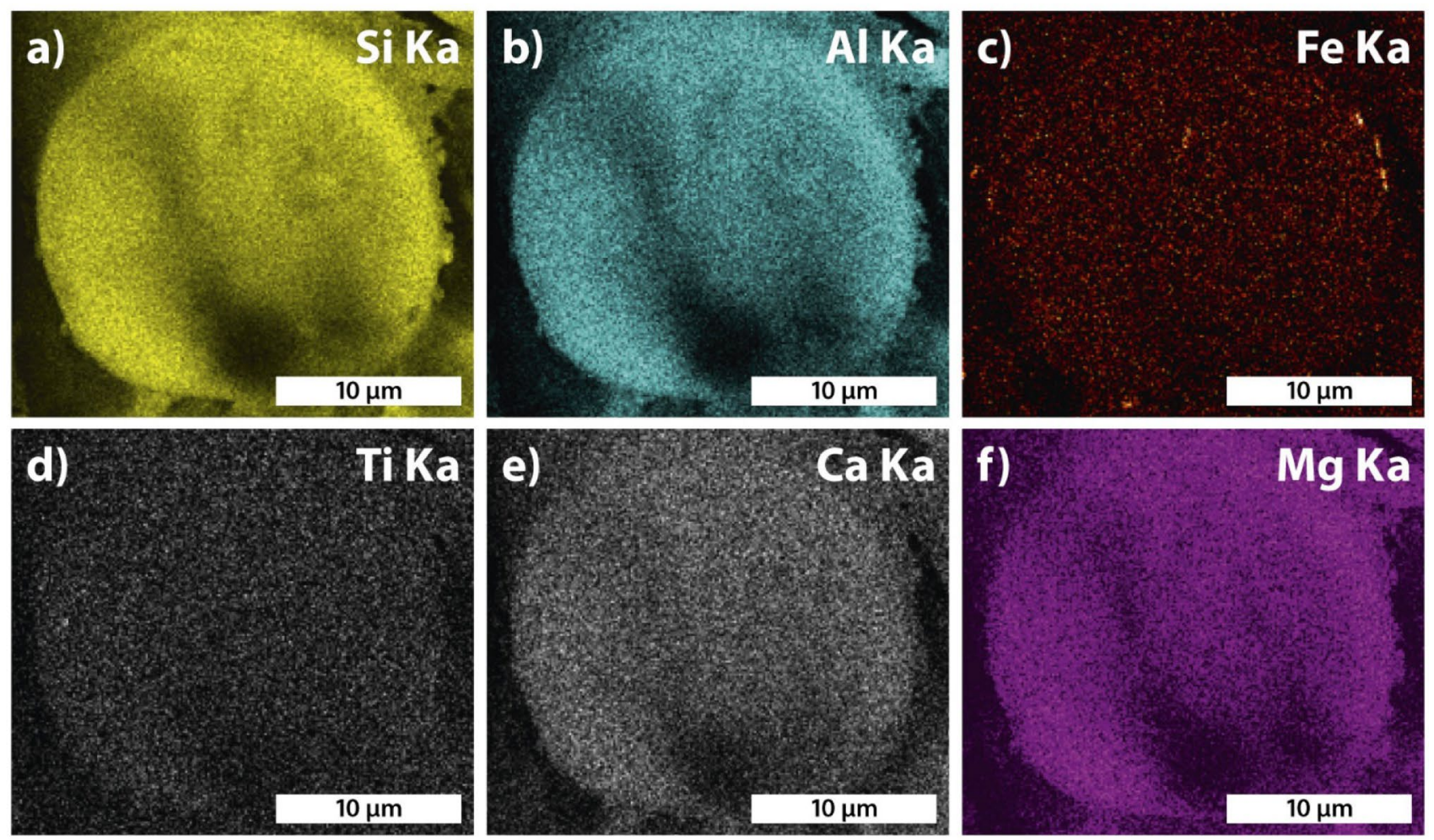

Fig. 15 HR-SEM images of chemical elements distribution over the BF radial cross section for type B basalt filaments
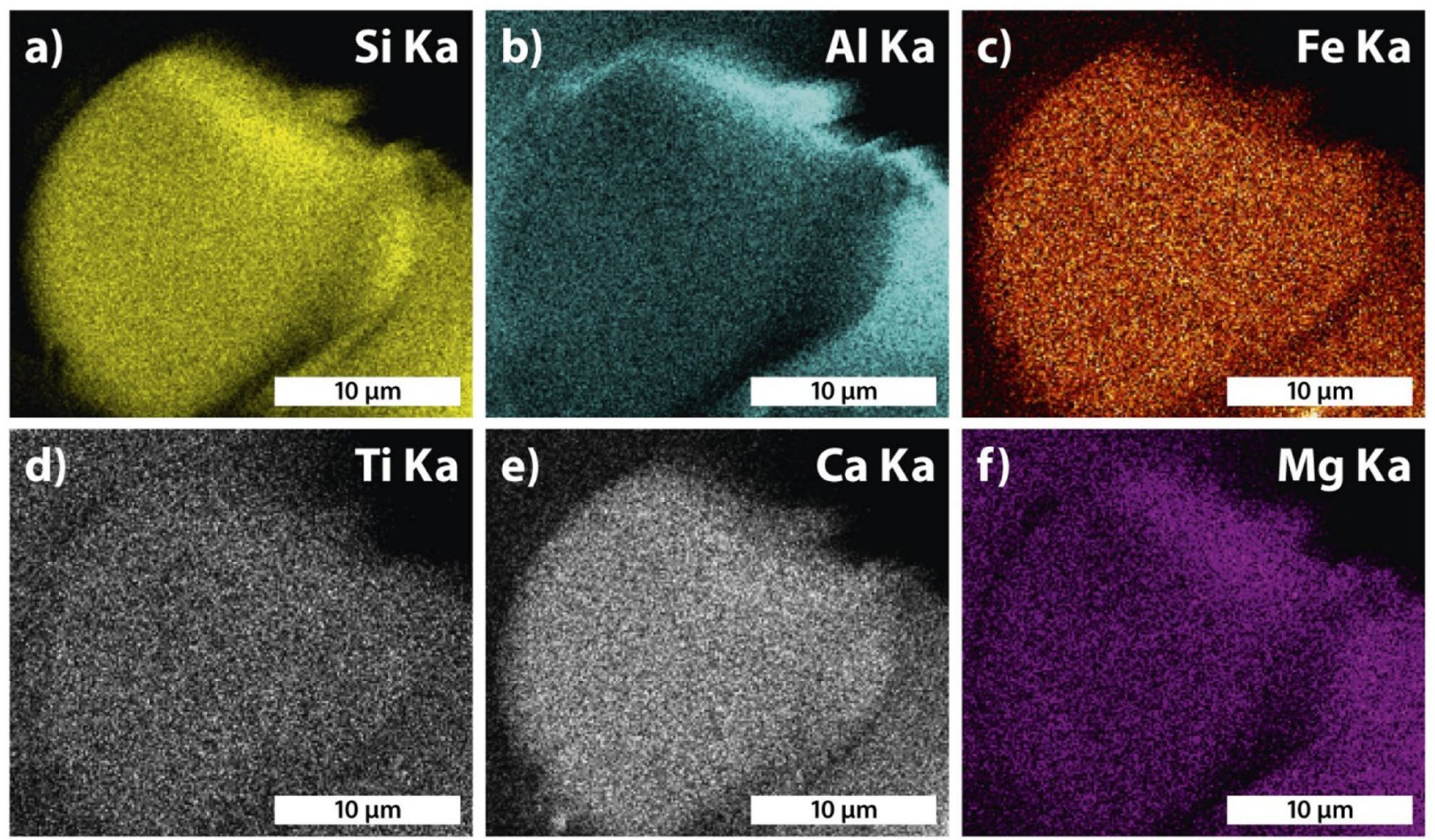

Fig. 16 HR-SEM images of chemical elements distribution over the BF radial cross section for type $C$ basalt filaments 
basalt fibers to alkaline action in concrete. The chemical composition plays a decisive role;

- Despite the high mechanical properties of thinner basalt fibers, with the "wrong" content of the chemical composition, they undergo significant degradation in an alkaline environment and, as a result, significantly lose their mechanical characteristics;

- By choosing the right raw materials for the production of basalt fibers, the fiber resistance to aggressive alkaline environment can be significantly increased.

However, the effects of the important parameters, such as low mechanical properties of type $C$ basalt fiber and increased fiber breakage of type $C$ basalt fiber, cannot be readily separated out and clearly evaluated from the existing research for improvement of concrete secondary reinforcement. Further research, carefully designed to target selected parameters, is necessary to fill the mentioned question.

Acknowledgements This research was supported by Horizon 2020 ERA-NET Support Programme, Research Grant Agreement No 7.93/18/7 ("Development of Boron-Infused Basalt-Fiber Reinforced Concrete for Nuclear and Radioactive Waste Management Applications"). Implementation of activities was described in the Roadmap to Fusion during Horizon 2020 through a joint programme of the members of the EUROfusion consortium (2014-2020), Work Package PMI.

\section{Compliance with ethical standards}

Conflict of interest The authors declare that they have no conflict of interest.

\section{References}

1. Afroughsabet V, Biolzi L, Ozbakkaloglu T (2016) High-performance fiber-reinforced concrete: a review. J Mater Sci 51(14):6517-6551. https://doi.org/10.1016/j.cemconcomp .2016.08.001

2. Afroz M, Patnaikuni S, Venkatesan S (2017) Chemical durability and performance of modified basalt fiber in concrete medium. Constr Build Mater 154:191-203. https://doi.org/10.1016/j. conbuildmat.2017.07.153

3. Bentur A, Mindess S (2007) Fiber reinforced cementitious composites, 2nd edn. Taylor and Francis, London, p 625

4. Borhan TM (2013) Thermal and Mechanical Properties of Basalt Fibre Reinforced Concrete. Int J Civ Environ Eng 7(4):334-337. https://doi.org/10.5281/zenodo.1058277

5. Brik VB (1997) Basalt fiber composite reinforcement for concrete . Transportation Research Board, Washington, DC

6. Brik VB, Ramakrishnan V, Tolmare NS (1998) Performance evaluation of 3-D basalt fiber reinforced concrete and basalt rod reinforced concrete. Transportation Research Board, Washington, DC

7. Colombo C, Vergani L, Burman M (2012) Static and fatigue characterisation of new basalt fibre reinforced composites. Compos Struct 94(3):1165-1174. https://doi.org/10.1016/j.compstruct .2011 .10 .007
8. Deak T, Czigány T (2009) Chemical composition and mechanical properties of basalt and glass fibers: a comparison. Text Res J 79(7):645-651. https://doi.org/10.1177/0040517508095597

9. Dias DP, Thaumaturgo C (2005) Fracture toughness of geopolymeric concretes reinforced with basalt fibers. Cem Concr Compos 27(1):49-54. https://doi.org/10.1016/j.cemconcomp .2004.02.044

10. Fiore V, Scalici T, Di Bella G, Valenza A (2015) A review on basalt fibre and its composites. Compos B Eng 74:74-94. https://doi. org/10.1016/j.compositesb.2014.12.034

11. Grdic ZJ, ToplicicCurcic GA, Ristic NS, Despotovic IM (2012) Abrasion resistance of concrete micro-reinforced with polypropylene fibers. Constr Build Mater 27(1):305-312. https://doi. org/10.1016/j.conbuildmat.2011.07.044

12. Gulik VI, Biland AB (2012) The use of basalt, basalt fibers and modified graphite for nuclear waste repository. In: Proceedings of international waste management conference (WM2012), Phoenix, Arizona, US, 26 February-1 March, 2012

13. Hannant DJ (2003) Fibre-reinforced concrete. Adv Concr Technol 4:1-17. https://doi.org/10.1016/B978-075065686-3/50292-5

14. Ipbüker C, Nulk H, Gulik V, Biland A, Tkaczyk AH (2015) Radiation shielding properties of a novel cement-basalt mixture for nuclear energy applications. Nucl Eng Des 284:27-37. https:// doi.org/10.1016/j.nucengdes.2014.12.007

15. Jiang C, Fan K, Wu F, Chen D (2014) Experimental study on the mechanical properties and microstructure of chopped basalt fibre reinforced concrete. Mater Des 58:187-193. https://doi. org/10.1016/j.matdes.2014.01.056

16. Jigiris DD, Mahova MF (2002) The bases of producing of basalt roving and products. Teploenergetic, vol 417. KamennyVek, , Moscow ((in Russian))

17. Kabay N (2014) Abrasion resistance and fracture energy of concretes with basalt fiber. Constr Build Mater 50:95-101. https:// doi.org/10.1016/j.conbuildmat.2013.09.040

18. Karahan O, Atiş CD (2011) The durability properties of polypropylene fiber reinforced fly ash concrete. Mater Des 32(2):10441049. https://doi.org/10.1016/j.matdes.2010.07.011

19. Li W, Xu J (2009) Mechanical properties of basalt fiber reinforced geopolymeric concrete under impact loading. Mater Sci Eng A 505(1-2):178-186. https://doi.org/10.1016/j.msea.2008.11.063

20. Li Z, Perez Lara MA, Bolander JE (2006) Restraining effects of fibers during non-uniform drying of cement composites. Cem Concr Res 36(9):1643-1652. https://doi.org/10.1016/j.cemco nres.2006.04.001

21. Lipatov YV, Gutnikov SI, Manylov MS, Zhukovskaya ES, Lazoryak BI (2015) High alkali-resistant basalt fiber for reinforcing concrete. Mater Des 73:60-66. https://doi.org/10.1016/j.matde s.2015.02.022

22. Liu J, Yang J, Chen M, Lei L, Wu Z (2018) Effect of SiO2, Al2O3 on heat resistance of basalt fiber. Thermochim Acta 660:56-60. https://doi.org/10.1016/j.tca.2017.12.023

23. Lopresto V, Leone C, De Lorio I (2011) Mechanical characterisation of basalt fibre reinforced plastic. Compos B Eng 42(4):717723. https://doi.org/10.1016/j.compositesb.2011.01.030

24. Manikandan V, WinowlinJappes JT, Suresh Kumar SM, Amuthakkannan P (2012) Investigation of the effect of surface modifications on the mechanical properties of basalt fibre reinforced polymer composites. Compos B Eng 43(2):812-818. https://doi. org/10.1016/j.compositesb.2011.11.009

25. Monaldo E, Nerilli F, Vairo G (2019) Basalt-based fiber-reinforced materials and structural applications in civil engineering. Compos Struct 214:246-263. https://doi.org/10.1016/j.compstruct .2019 .02 .002

26. Nanni A (1991) Fatigue behaviour of steel fiber reinforced concrete. Mater Cem Concr Compos 13(4):239-245. https://doi. org/10.1016/0958-9465(91)90029-H 
27. Novitskii AG, Efremov MV (2013) Technological aspects of the suitability of rocks from different deposits for the production of continuous basalt fiber. Glass Ceram 69(11-12):409-412. https ://doi.org/10.1007/s10717-013-9491-z

28. Qian CX, Stroeven P (2000) Development of hybrid polypropylene-steel fibre-reinforced concrete. Cem Concr Res 30(1):63-69. https://doi.org/10.1016/S0008-8846(99)00202-1

29. Ramachandran BE, Velpari V, Balasubramanian N (1981) Chemical durability studies on basalt fibres. J Mater Sci 16:3393-3397. https://doi.org/10.1007/BF00586301

30. Sim J, Park C, Moon DY (2005) Characteristics of basalt fiber as a strengthening material for concrete structures. Compos B Eng 36(6-7):501-504. https://doi.org/10.1016/j.composites b.2005.02.002

31. Sivakumar A, Santhanam M (2007) Mechanical properties of high strength concrete reinforced with metallic and nonmetallic fibres. Cem Concr Compos 29(8):603-608. https://doi. org/10.1016/j.cemconcomp.2007.03.006

32. Skarżyński $Ł$, Suchorzewski J (2018) Mechanical and fracture properties of concrete reinforced with recycled and industrial steel fibers using digital image correlation technique and X-ray micro computed tomography. Constr Build Mater 183:283-299. https://doi.org/10.1016/j.conbuildmat.2018.06.182

33. Smarzewski P (2020) Flexural toughness evaluation of basalt fibre reinforced HPC beams with and without initial notch. Compos Struct 235:111769. https://doi.org/10.1016/j.comps truct.2019.111769

34. Tang C, Jiang H, Zhang X, Li G, Cui J (2018) Corrosion behavior and mechanism of basalt fibers in sodium hydroxide solution. Materials 11: 1381. https://doi:10.3390/ma11081381

35. Thorhallsson ER, Hinriksson Gl, Snæbjörnsson JT (2017) Strength and stiffness of glulam beams reinforced with glass and basalt fibres. Compos B Eng 115:300-307. https://doi.org/10.1016/j. compositesb.2016.09.074

36. Walraven JC (2009) High performance fiber reinforced concrete: progress in knowledge and design codes. Mater Struct Mater Constr 42(9):1247-1260. https://doi.org/10.1617/s1152 7-009-9538-3

37. Zhao Q, Dong J, Pan $\mathrm{H}, \mathrm{Hao} \mathrm{S}$ (2010) Impact behavior of basalt fiber reinforced concrete. Acta Mater Compos Sin 27(6):120-125

38. Zieliński K, Olszewski P (2005) The impact of basaltic fibre on selected physical and mechanical properties of cement mortar. Concr Precast Plant Technol 71(3):28-33

39. Zimin DE, Tatarintseva OS (2010) Influence of glass chemical composition on the resistance of basalt fibers to aggressive environments. Polzunovsky vestnik 4(1):247-251

40. Zollo RF (1997) Fiber-reinforced concrete: an overview after 30 years of development. Cem Concr Compos 19(2):107-122. https ://doi.org/10.1016/S0958-9465(96)00046-7

41. Zorla E, Ipbüker C, Biland A, Kiisk M, Kovaljov S, Tkaczyk AH, Gulik V (2017) Radiation shielding properties of high performance concrete reinforced with basalt fibers infused with natural and enriched boron. Nucl Eng Des 313:306-318. https://doi. org/10.1016/j.nucengdes.2016.12.029

42. Zorla E, Ipbuker C, Gulik V, Kovaljov S, Kiisa M, Biland A, Tkaczyk $\mathrm{AH}$ (2016) Optimization of basalt fiber in concrete composite for industrial application in Estonia. Fresenius Environ Bull 25(1):355-364

Publisher's Note Springer Nature remains neutral with regard to jurisdictional claims in published maps and institutional affiliations. 